\title{
CARACTERIZAÇÃO GEOLÓGICA DA DISTRIBUIÇÃO DE RESERVATÓRIOS CARBONÁTICOS ALBIANOS, SUDOESTE DA BACIA DE CAMPOS (BRASIL).
}

\author{
GEOLOGICAL CHARACTERIZATION OF THE DISTRIBUTION OF ALBIAN CARBONATIC \\ RESERVOIRS, SOUTHWEST OF CAMPOS BASIN (BRAZIL).
}

\author{
Leonardo HABERMANN ${ }^{1}$, Maria Gabriela Castillo VINCENTELLI ${ }^{2}$, Sergio Antonio \\ Cáceres CONTRERAS ${ }^{2}$, José Alexandre de Jesus PERINOTTO ${ }^{3}$ \\ ${ }^{1}$ Curso de Pós-Graduação em Geociências, Instituto de Geociências e Ciências Exatas, UNESP, Rio Claro, SP. \\ Endereço eletrônico: leonardo.habermann@yahoo.com.br \\ ${ }^{2}$ Pesquisadores da Fundunesp, Laboratório de Integração de Dados Sísmicos e Geológicos, Instituto de Geociências e Ciências \\ Exatas, UNESP, Rio Claro, SP. Endereços eletrônicos: g_vicentelli@yahoo.es, sacaceres@gmail.com \\ ${ }^{3}$ Instituto de Geociências e Ciências Exatas, Departamento de Geologia Aplicada, UNESP, Rio Claro, SP. \\ Endereço eletrônico: perinoto@rc.unesp.br

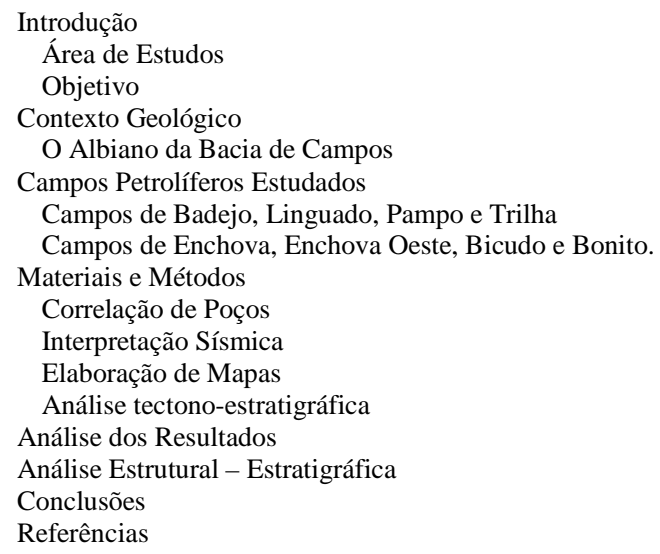

RESUMO - Na região sudoeste da Bacia de Campos, a presença de reservatórios carbonáticos é condicionada por feições estruturai e estratigráficas. Neste sentido, pretende-se caracterizar a distribuição e tipo de play associado ao principal reservatório desta natureza, identificado com base numa análise geológica - geofísica em área que contém oito campos petrolíferos maduros, situados na região de estudos. O presente trabalho visa à caracterização de mecanismos que possibilitem as acumulações locais de hidrocarbonetos num nível reservatório principal, de ocorrência generalizada na área. Este objetivo foi atingido por meio da análise de perfis geofísicos, correlação de poços e interpretação de dados sísmicos $2 \mathrm{D}$ e 3D, que permitiram constatar a predominância de armadilhas estruturais nos campos de Linguado e Pampo, relacionadas a uma feição dômica regional, e em Bicudo, onde o nível produtor ocorre sobre uma estrutura do tipo rollover. Já em meio aos campos de Enchova e Bonito, armadilhas mistas foram descritas para as acumulações observadas, com presença de feições elevadas (componente estrutural) associadas à variação lateral de fácies em baixos deposicionais (componente estratigráfica). Verificou-se que, embora o Canyon de Enchova, de idade oligocênica, constitua uma feição estratigráfica de ampla ocorrência nos campos de Enchova, Enchova Oeste, Bicudo e Bonito, importante no trapeamento de hidrocarbonetos em estratos do Paleógeno/Neógeno, na região estudada observa-se que esta feição não exerce controle sobre os níveis reservatórios da Formação Quissamã.

Palavras-chave: Bacia de Campos, Formação Quissamã, Trapas, Perfis de Poço.

\begin{abstract}
In the southwestern region of the Campos Basin, carbonate reservoirs are conditioned by structural and stratigraphic features. In this sense, it is intended to characterize the distribution and type of play associated to the main reservoir of this nature, identified based on a geological-geophysical analysis in an area that contains eight mature oil fields located in the region of studies. The present work aims the characterization of mechanisms that allow the local accumulations of hydrocarbons in a main reservoir level, of generalized occurrence in the area. This objective was reached through the analysis of geophysical profiles, well correlation and 2D and 3D Seismic interpretation, which allowed the verification of predominance of structural traps in Pampo and Linguado fields, related to a regional dome feature, and in Bicudo, where the producer level occurs on a rollover structure. In Enchova and Bonito fields, mixed traps were described for the observed accumulations, with presence of elevated features (structural component) associated to lateral facies variation in depositional lows (stratigraphic component). It was verified that, although the Enchova Canyon, of Oligocene age, constitutes a stratigraphic feature of wide occurrence in the Enchova, Enchova Oeste, Bicudo and Bonito, important in the hydrocarbon trapping of Paleogen / Neogen strata, in the region studied this feature does not control the reservoir levels of the Quissamã Formation.
\end{abstract}

Keywords: Campos Basin, Quissamã Formation, Traps, Well logs.

\section{INTRODUÇÃO}

A Bacia de Campos é considerada a mais prolífica do país, respondendo por cerca de 60\% da produção nacional de óleo em 2016, segundo dados da Agência Nacional do Petróleo - ANP (2016). As atividades comerciais na região iniciaram-se ao fim da 
década de 70, no campo de Enchova, seguido até 1981 por Garoupa, Pampo, Badejo e Linguado, situados na porção sudoeste da bacia (Bruhn et al., 2003).

Em todos estes campos, o primeiro nível reservatório explorado corresponde a calcarenitos mesoalbianos da Formação Quissamã, ainda hoje responsáveis por uma fatia considerável dos hidrocarbonetos extraídos da bacia.

Ao longo da última década, observa-se declínio na produção oriunda dos reservatórios pós-sal situados em campos petrolíferos maduros na Bacia de Campos, incluindo os calcarenitos citados.

Tal fato, aliado à escassez de novas jazidas, torna importantes os trabalhos que permitam a identificação de possíveis ocorrências de hidrocarbonetos ainda presentes em subsuperfície, possibilitando também a otimização da produção nestas áreas. Neste contexto, esta pesquisa contribui para melhor compreensão dos fatores que condicionaram as acumulações petrolíferas em meio a rochas carbonáticas albianas presentes na região sudoeste da Bacia de Campos.

\section{Área de Estudo}

A área de estudos deste trabalho se estende sobre oito campos petrolíferos maduros, situados na porção sudoeste da Bacia de Campos: Badejo, Bicudo, Bonito, Enchova, Enchova Oeste, Linguado, Pampo e Trilha (Figura 1).

As cotas batimétricas locais variam entre 90 m (Badejo) e 250 m (Bicudo), a uma distância mínima de 70 km em relação à costa sudeste do Brasil.

\section{Objetivo}

O objetivo desta pesquisa é a caracterização tectono-estratigráfica do principal nível reservatório existente em meio aos carbonatos albianos da Formação Quissamã, por meio da utilização de dados técnicos sísmicos e geofísicos.

Esta abordagem tem como intuito a descrição dos diferentes mecanismos que condicionaram a presença das acumulações petrolíferas na região.

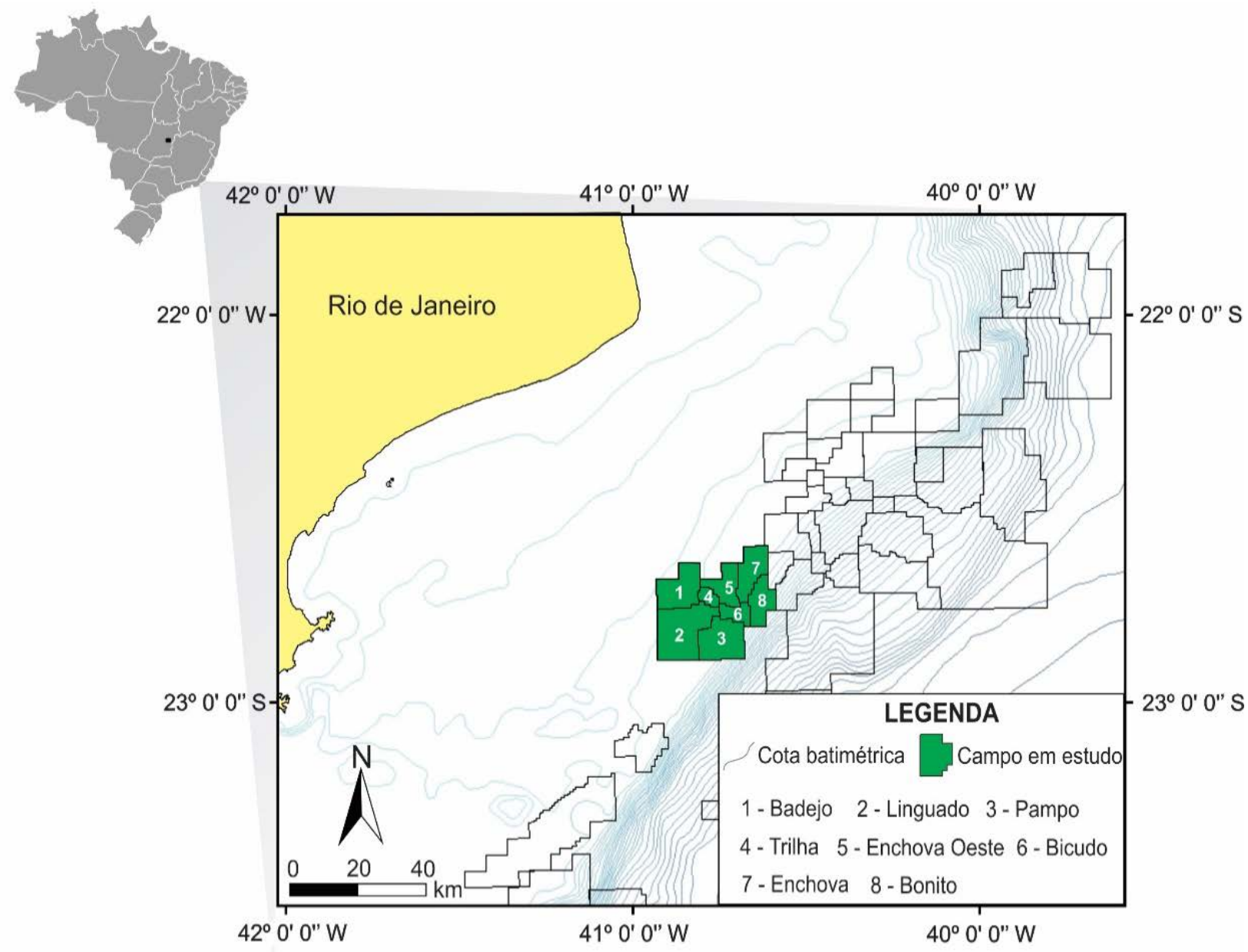

Figura 1 - Localização dos campos petrolíferos estudados em meio à Bacia de Campos. 


\section{CONTEXTO GEOLÓGICO}

A Bacia de Campos está limitada a norte, com a Bacia do Espírito Santo, pelo Arco de Vitória, e a sul, com a Bacia de Santos, pelo Alto de Cabo Frio. Ocupa uma área com cerca de $115.800 \mathrm{~km}^{2}$, dos quais apenas $500 \mathrm{~km}^{2}$ são emersos. Sua origem está relacionada à ruptura do Supercontinente Gondwana, iniciada a partir do Cretáceo Inferior.

Diversos autores abordaram a história evolutiva da Bacia de Campos (Asmus \& Porto, 1980; Chang et al., 1990; Rangel et al., 1994; Cainelli \& Mohriak 1998), destacando-se o trabalho de Winter et al. (2007), que corresponde à carta estratigráfica mais recente da bacia. Estes autores dividem a evolução tectono-estratigráfica regional em três supersequências, denominadas Rifte, Pós-Rifte e Drifte.

A Formação Quissamã, foco de estudos deste trabalho, está inclusa na supersequência Drifte, que corresponde ao estágio marinho franco da Bacia de Campos.

\section{O Albiano da Bacia de Campos}

O Albiano da Bacia de Campos está representado pela Formação Quissamã, depositada entre o Albiano inferior e o Albiano Médio, correspondendo à porção basal do Grupo Macaé. Consiste numa espessa seção carbonática que chega a atingir $800 \mathrm{~m}$ em algumas porções da bacia (Winter et al., 2007). Litologicamente, predominam calcarenitos e calcirruditos oolíticos, oncolíticos e peloidais, com intercalações crescentes de calcissiltitos, calcilutitos e margas em direção ao topo (Dias et al., 1990). A base desta unidade, na região sul e central da Bacia de Campos, apresenta-se geralmente dolomitizada, sendo denominada de Membro Búzios. O limite inferior da Formação Quissamã corresponde a uma superfície discordante, com contato abrupto entre os carbonatos albianos e os depósitos evaporíticos da Formação Retiro, de idade aptiana. Já o limite superior equivale a uma superfície de inundação máxima, expressa em marcos estratigráficos regionais denominados de Marco Beta e Marco Glauconítico (porção proximal), datados do Mesoalbiano.

Capeando a Formação Quissamã, a Formação Outeiro é composta por calcilutitos, notadamente mudstones bioclásticos ricos em microfósseis, e intercalações de margas e folhelhos, chegando a $300 \mathrm{~m}$ de espessura (Dias-Brito, 1982, Winter et al., 2007).

Segundo Spadini et al. (1988) e Guardado et al. (1989), o modelo deposicional referente à Formação Quissamã inclui, na margem sudoeste da bacia, ambientes lagunares e de praia, que evoluem gradualmente para uma plataforma carbonática regional, com bancos oolíticos alongados no sentido NE-SW. A geomorfologia deposicional seria a de uma rampa carbonática, com mergulho baixo de rumo leste-nordeste, fortemente afetada por movimentos halocinéticos a partir do limite Eo-Mesoalbiano (Demercian et al., 1993). Esta tectônica adiastrófica influencia a morfologia do substrato, levando à formação de baixos deposicionais e áreas elevadas, que controlam a variação faciológica observada ao longo da Formação Quissamã.

\section{CAMPOS PETROLÍFEROS ESTUDADOS}

\section{Campos de Badejo, Linguado, Pampo e Trilha}

Nesta região, a Formação Quissamã inclui níveis produtores apenas em Linguado e Pampo, não tendo sido constatadas ocorrências de relevância econômica em Badejo e Trilha até o momento (Milani \& Araujo, 2003; Bruhn et al., 2003).

Os reservatórios carbonáticos locais exibem controle estrutural e estratigráfico. O primeiro está relacionado à variação lateral e vertical de fácies, distribuídas em ciclos de raseamento ascendente. Estes ciclos caracterizam-se pela deposição de calcissiltitos e calcarenitos microoncolíticos muito cimentados na porção basal, gradando para calcarenitos oolíticos e oncolíticos no topo
(Baumgarten \& Scuta 1988). Os calcissiltitos na base dos ciclos de raseamento funcionam como selantes, ao passo que, para os reservatórios situados no topo da Formação Quissamã, enfocados neste estudo, os calcilutitos e margas da Formação Outeiro atuam como camada impeditiva à passagem de hidrocarbonetos.

O controle estrutural está ligado à presença de falhas lístricas normais e almofadas de sal, que geram estruturas do tipo "casco de tartaruga", rollover e anticlinais (Lopes, 2004). A figura 2 representa uma seção esquemática entre os campos de Badejo e Linguado, representando o reservatório carbonático neste último. 


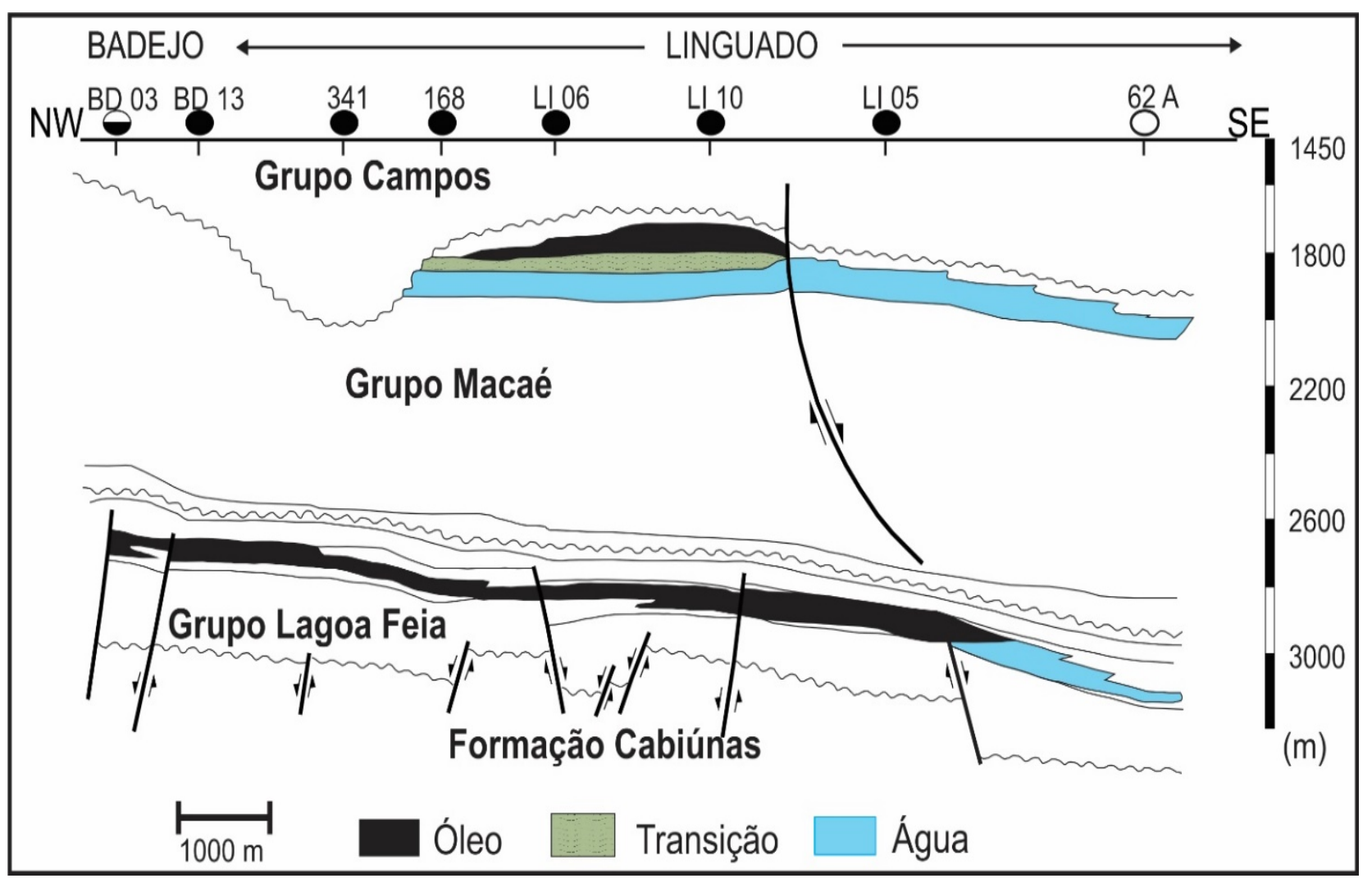

Figura 2 - Seção esquemática entre os campos de Linguado e Badejo, representando acumulações de óleo em coquinas (Gr. Lagoa Feia) e carbonatos albianos (Gr. Macaé). Fonte: Adaptado de Guardado et al. (1989).

\section{Campos de Enchova, Enchova Oeste, Bicudo e Bonito.}

Dentre estes quatro campos, apenas Enchova Oeste não apresenta acumulações petrolíferas importantes em meio à Formação Quissamã. Os mecanismos que propiciaram a acumulação de óleo e gás nos carbonatos de Enchova são majoritariamente de natureza estratigráficoestrutural, com atuação significativa de falhas normais na migração e trapeamento de hidrocarbonetos.

São muito comuns estruturas do tipo casco de tartaruga (Figueiredo \& Mohriak 1984), bem como feições dômicas formadas a partir da movimentação salina (Guardado et al., 1989).

Já na região dos campos de Bicudo e Bonito, predominam mecanismos majoritariamente estruturais. O limite Bicudo - Bonito é marcado, na porção sudoeste, por uma falha com rejeito superior a $100 \mathrm{~m}$ cujo bloco baixo separa as duas áreas (Baumgarten, 1986). Outro falhamento, no extremo oeste de Bicudo, funciona como limite entre este campo e a área de Pampo.

O Canyon de Enchova, descrito por Antunes et al. (1988), corresponde a uma importante feição estratigráfica na região limítrofe entre os campos de Bicudo e Bonito, condicionando a presença de acumulações petrolíferas em estratos turbidíticos do Paleógeno, como ilustrado pela figura 3 .

Feições estruturais dômicas são importantes reservatórios no campo de Bonito (Guardado et al., 1989), ao passo que falhamentos normais e lístricos representam os principais mecanismos de trapeamento na área de Bicudo (Baumgarten, 1986).

\section{MATERIAIS E MÉTODOS}

A base de informações utilizada para a elaboração deste estudo foi adquirida junto à ANP, sendo de natureza gratuita e acesso público para fins acadêmicos. O banco de dados organizado é constituído pelos perfis geofísicos de 33 poços, compostos por quatro curvas básicas em formato (.las): GR (Raio Gama), DT (sônico), ILD (resistividade) e RHOB (densidade), bem como suas respectivas pastas de poço e perfis compostos. Foram utilizadas também 60 linhas sísmicas 2D e um volume sísmico 3D que compreende cerca de $90 \mathrm{~km}^{2}$ em área. A Figura 4 ilustra a disposição espacial dos dados analisados. $\mathrm{O}$ método aplicado durante o desenvolvimento deste estudo inclui quatro etapas principais, descritas a seguir. 


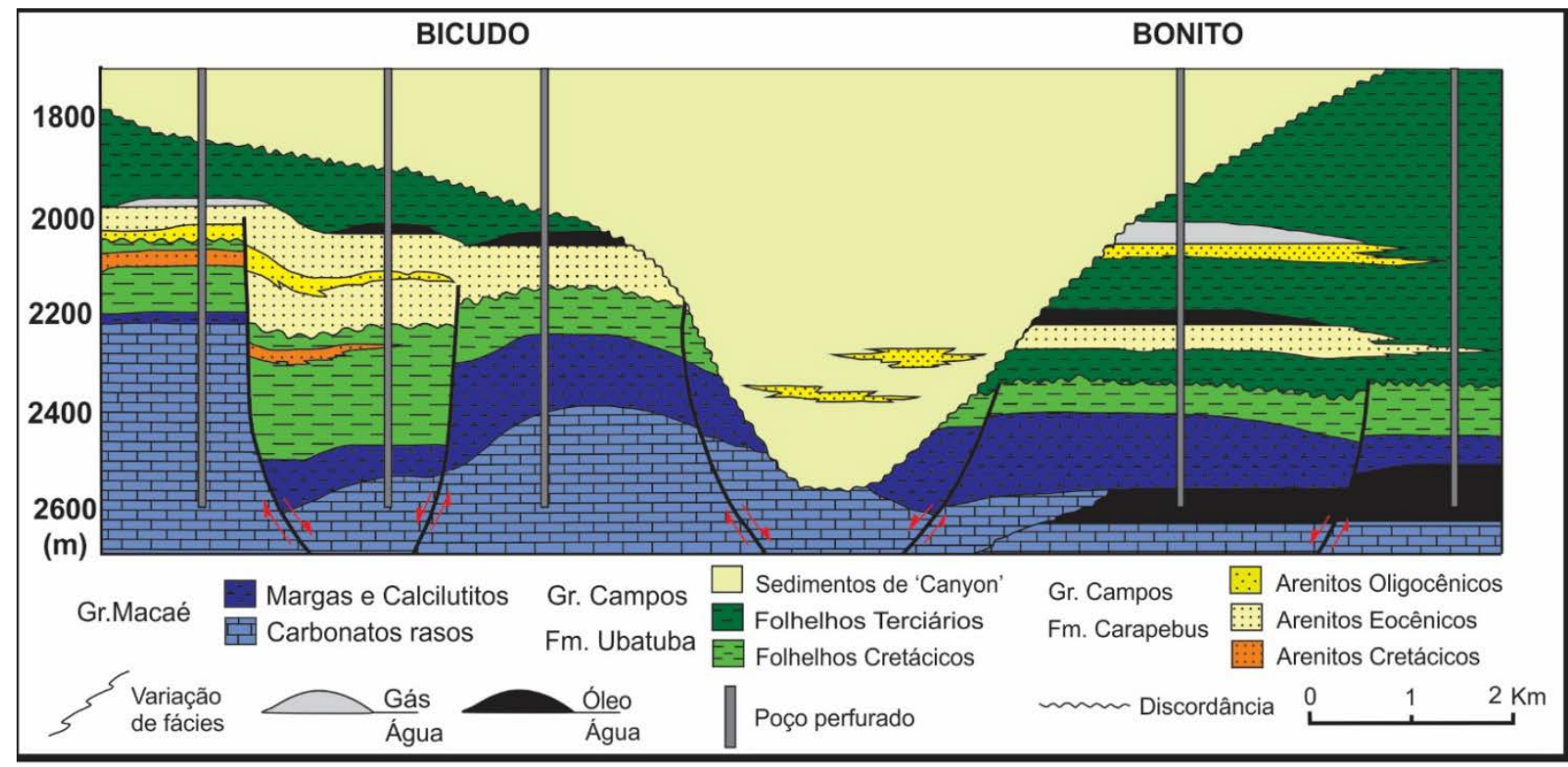

Figura 3 - Seção esquemática entre os campos de Bicudo e Bonito. Fonte: Guardado \& Arso (1984 apud Guardado et al. (1989).

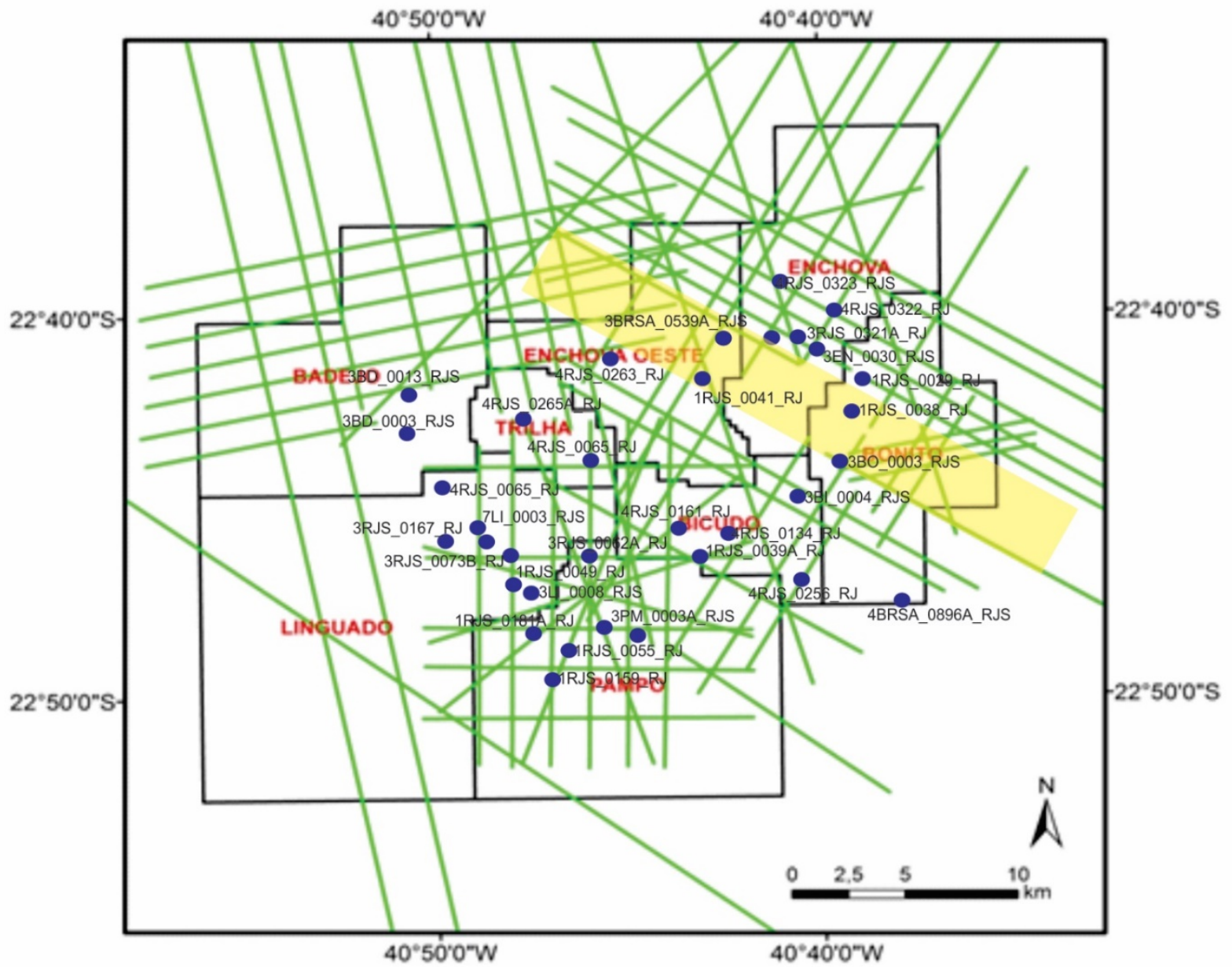

Figura 4 - Disposição espacial das linhas sísmicas 2D (em verde), volume sísmico 3D (em amarelo) e poços (em azul) ao longo da área estudada.

\section{Correlação de Poços}

Para possibilitar a correlação entre os níveis estratigráficos de interesse, foi necessária a conversão dos arquivos (.las) em gráficos, os quais expressam os valores das propriedades de cada curva em função da profundidade amostrada.

Em seguida, foram delimitados os principais 
níveis estratigráficos em cada poço, de acordo com a variação das propriedades físicas na profundidade considerada.

A correlação entre os poços estudados foi elaborada a partir de quatro seções estratigráficas (Figura 5), que permitem determinar a geometria e variações na espessura e propriedades físicas das unidades abordadas.
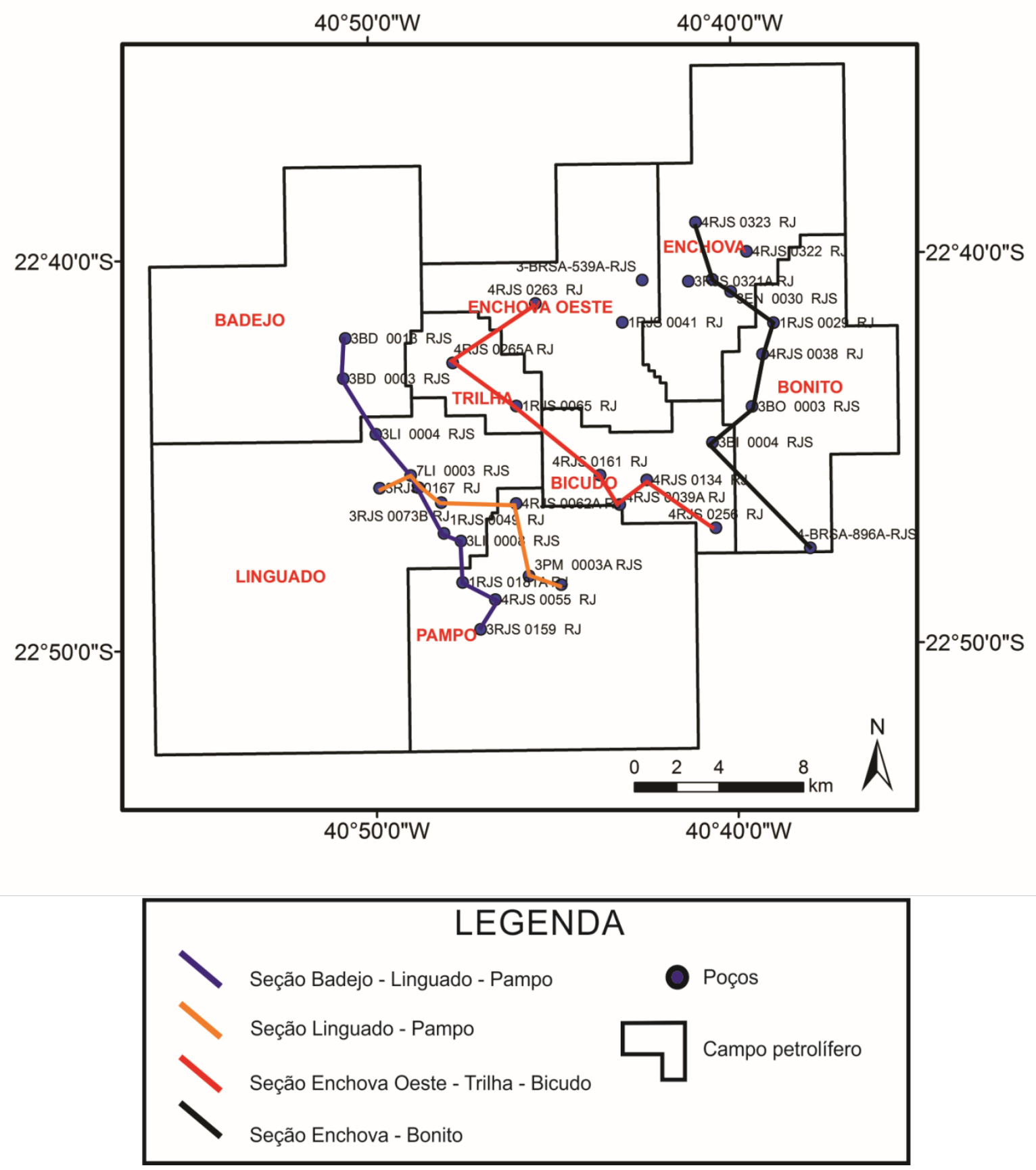

Figura 5 - Localização das seções estratigráficas confeccionadas.

\section{Interpretação Sísmica}

Os dados sísmicos 2D e 3D foram carregados e interpretados no software Decision Space, da Landmark - plataforma R5000.

Para calibração entre os níveis estratigráficos identificados nas seções e os refletores sísmicos observados, utilizaram-se os perfis sônicos de cada poço. A partir destes, é possível realizar a conversão dos dados expressos em metros (m) nos poços para milissegundos (ms), conforme apresentado nos dados sísmicos utilizando velocidade intervalar.

A figura 6 exemplifica a divisão de intervalos a partir do perfil sônico e a respectiva velocidade média calculada. Para os poços que possuem tanto o perfil de densidade quanto o sônico completos, também foram elaborados os sismogramas sintéticos, que correspondem a curvas sísmicas geradas pelo software Decision Space. 


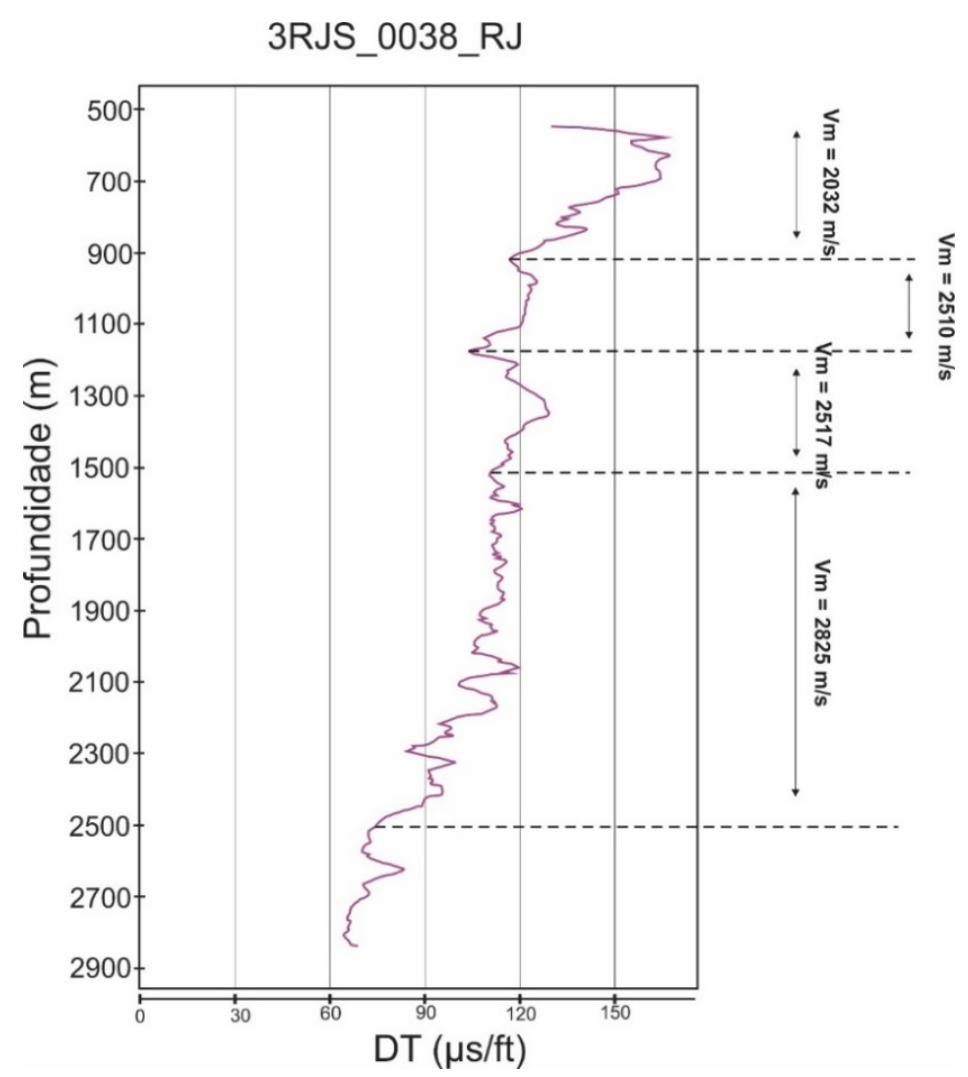

Figura 6 - Exemplo de intervalo selecionado por meio da correlação de perfis sônicos, e o cálculo das respectivas velocidades médias de cada um. Dados referentes ao poço 1RJS_0038_RJ.

Após a calibração dos dados sísmicos com os dados de poço, realiza-se a interpretação das linhas 2D e volumes 3D, com identificação dos níveis equivalentes à Formação Cabiúnas (embasamento econômico da Bacia de Campos), Grupo Lagoa Feia (equivalente à Supersequência Rifte), Formação Retiro (depósitos evaporíticos), além das formações Quissamã e Outeiro. Os dados 3D foram analisados numa malha $3 \times 3$ na direção de inlines e crosslines. Nesta etapa, foram identificados os refletores equivalentes aos níveis estratigráficos de interesse, bem como as estruturas importantes para a compreensão do arcabouço geológico local (falhas, grabéns, horsts, rollover).

\section{Elaboração de Mapas}

Os horizontes cronoestratigráficos interpretados foram utilizados para a geração dos mapas de contorno estrutural da Formação Quissamã por meio do software Decision Space. A profundidade das camadas está expressa em tempo (milissegundos), uma vez que a conversão destes valores em metros varia de acordo com a espessura e natureza da coluna sedimentar sobreposta à superfície considerada, tornando aproximações pouco fiéis aos reais valores que seriam encontrados.

\section{Análise Tectono-Estratigráfica}

Nesta etapa, realizou-se a integração dos resultados obtidos anteriormente, com 0 intuito de caracterizar as feições determinantes para a presença de acumulações petrolíferas. Enfatizou-se a descrição do tipo e continuidade das trapas dominantes em cada porção da região abordada, apresentando os mecanismos responsáveis pela presença destas feições.

\section{ANÁLISE DOS RESULTADOS}

A análise dos perfis geofísicos permitiu a delimitação das formações Retiro, Quissamã (incluindo o Membro Búzios), e Outeiro, além da base da Formação Ubatuba e depósitos arenosos da Formação Carapebus.

Cada uma das quatro correlações estratigráficas segue descrita abaixo.

As figuras 7 e 8 ilustram, respectivamente, as seções Enchova Oeste - Trilha - Bicudo e Enchova - Bicudo - Bonito. Ambas têm orientação NW-SE, compondo seções do tipo dip. 


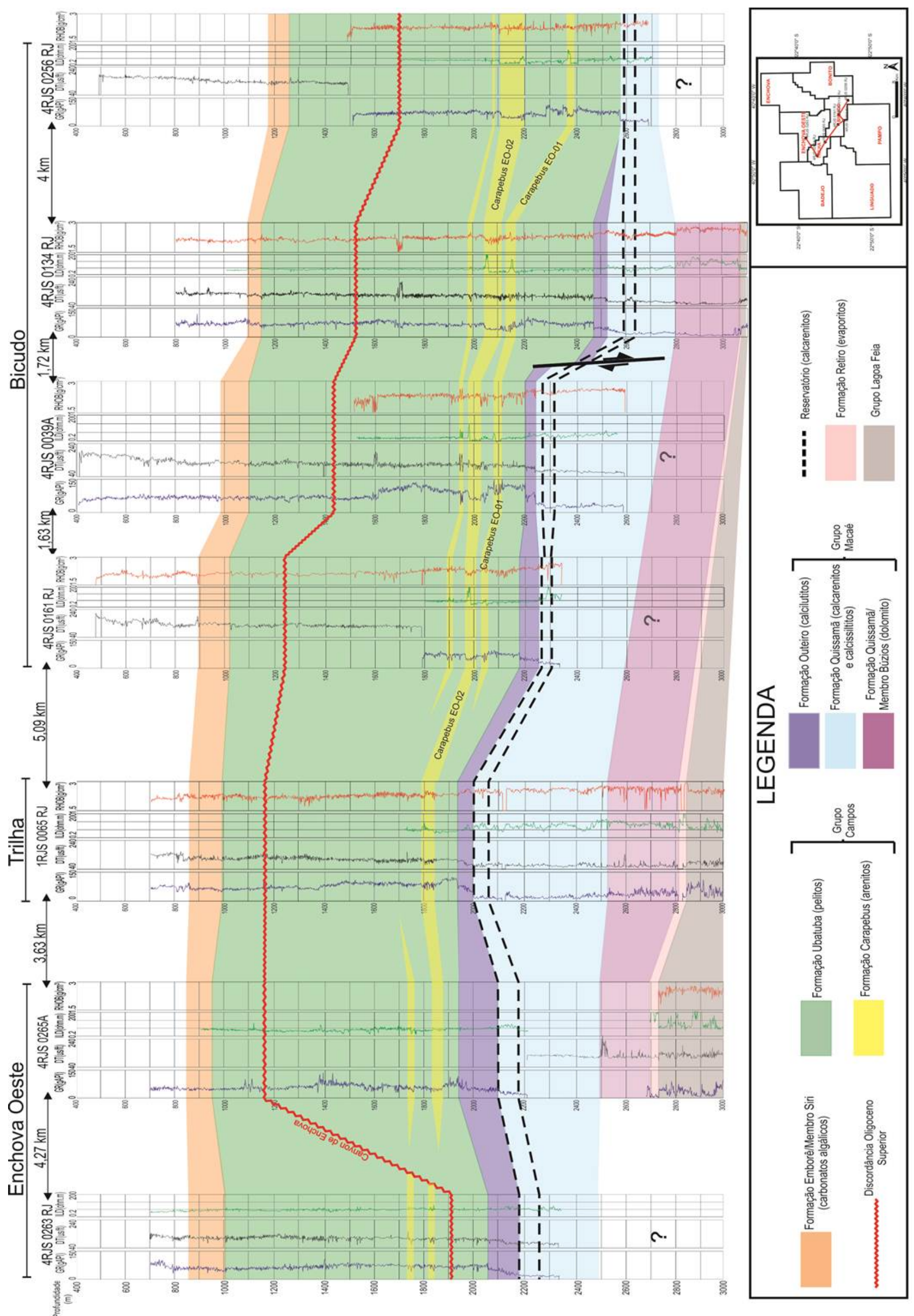

Figura 7 - Seção Enchova Oeste - Trilha - Bicudo. 


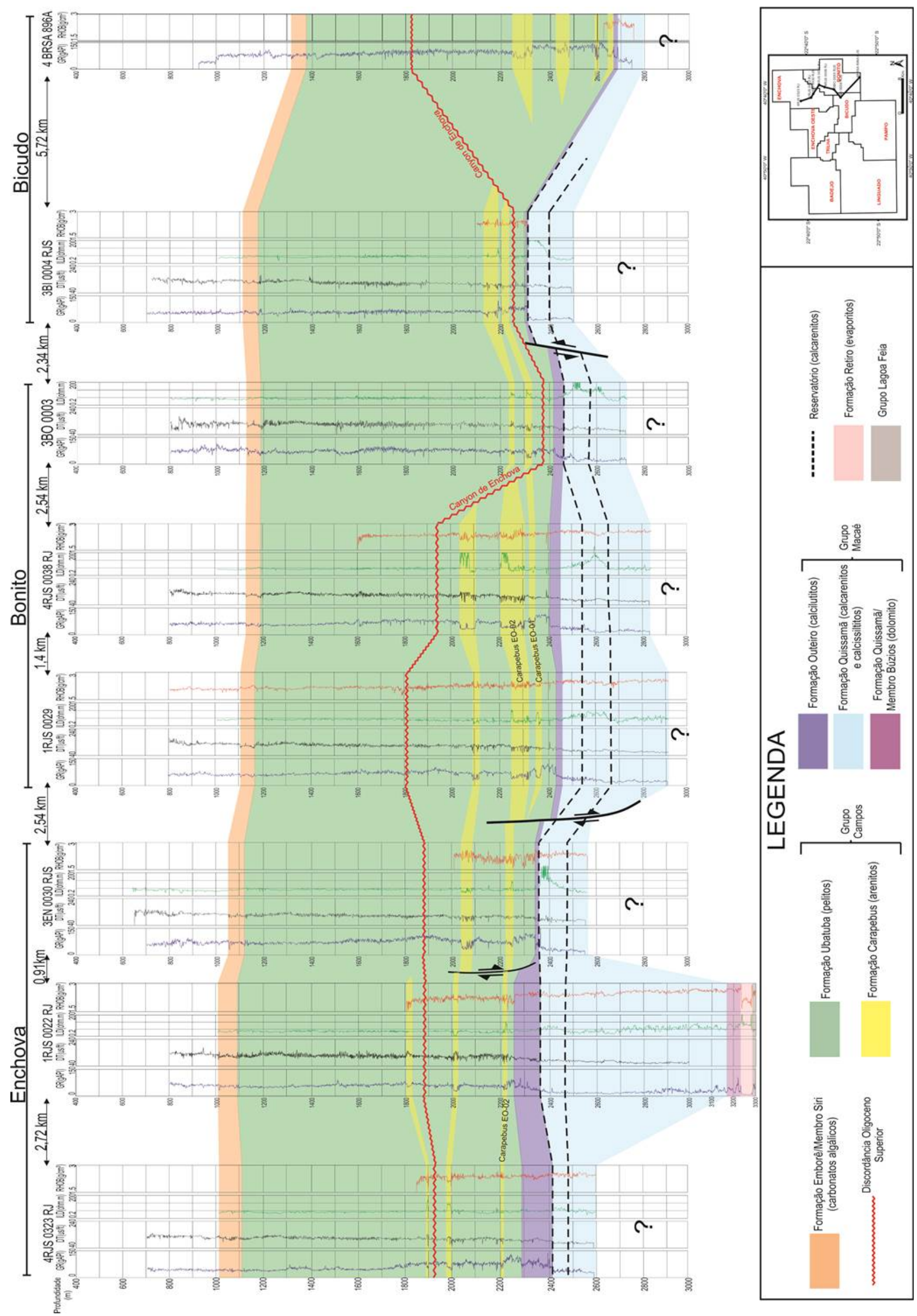

Figura 8 - Seção Enchova - Bonito - Bicudo. 
Em ambas as seções, os depósitos evaporíticos da Formação Retiro mostram espessura reduzida, entre 5 e $30 \mathrm{~m}$, com mergulho em torno de $2^{\circ}$, de rumo leste sudeste. Caracterizam-se por valores abaixo de 40 API no perfil de radioatividade, além de alta resistividade. Os dolomitos do Membro Búzios, que recobrem de maneira discordante as rochas evaporíticas, apresentam o mesmo compotamento estrutural, exibindo registro tipicamente "caótico" nos perfis de resistividade e radioatividade. A espessura deste litotipo varia de $10 \mathrm{~m}$ (em Enchova Oeste) a $300 \mathrm{~m}$ (região de Bicudo), espessando-se em direção à região sudeste da área estudada.

A porção superior da Formação Quissamã apresenta mergulho geral baixo, de rumo lestesudeste, com assinaturas no perfil de radioatividade inferiores a $50{ }^{\circ} \mathrm{API}$. Estas tendem a serem ainda menores (em torno de 40 API) próximos ao contato com a Formação Outeiro, coincidindo com valores mais baixos de densidade e, ocasionalmente, registros de resistividade superiores a 20 ohm.m. A associação destes fatores permite delimitar o principal nível reservatório da Formação Quissamã na porção superior da unidade, fato confirmado pela análise das pastas e perfis compostos dos poços 3BI_0004, 4RJS_0038, 4RJS_0161 e 3EN_0030.

Pode-se observar nas duas primeiras seções o abatimento pronunciado da Formação Quissamã na região dos campos de Bicudo e Bonito, em função da presença de falhamentos normais e lístricos, que ocorrem também em meio ao campo de Enchova.

Sobrepostos ao Grupo Macaé, foram constatados os depósitos de margas e folhelhos da Formação Ubatuba, com valores de radioatividade superiores a 60 API. Inseridos em meio a estes litotipos, ocorrem depósitos arenosos da Formação Carapebus, marcados por registros de média inferior a 50 API nos perfis de raios gama. A análise das seções evidenciou que a superfície erosiva do Canyon de Enchova não atinge os estratos das formações Quissamã e Outeiro, condicionando apenas acumulações ao nível dos turbiditos paleógenos e neógenos.

Os campos situados na porção sudoeste da área de estudo (Badejo, Linguado e Pampo) foram analisados com base em duas correlações principais: Badejo - Linguado - Pampo (Figura 9) e Linguado - Pampo (Figura 10). Ambas consistem em seções dip, orientadas segundo a direção NW-SE.

O primeiro nível estratigráfico identificado nestas correlações foi a Formação Retiro, com mergulho inferior a $2^{\circ}$ e espessura variável entre 5 e $35 \mathrm{~m}$, adelgaçando-se em direção ao campo de Pampo. Os dolomitos basais do Membro Búzios, sobrepostos aos evaporitos, exibem o padrão caótico já descrito para os perfis de radioatividade e resistividade, acompanhando o comportamento estrutural da Formação Retiro. Mostram espessamento em direção à porção noroeste do campo de Pampo, onde atingem cerca de $350 \mathrm{~m}$.

Acima dos dolomitos, a Formação Quissamã é composta por calcarenitos e calcissiltitos, com predomínio dos primeiros, conforme constatado nas pastas e perfis de radioatividade (com valor médio em torno de $20^{\circ}$ API). Sua espessura tende a ser maior na região limítrofe entre os campos de Linguado e Pampo, onde chega a $650 \mathrm{~m}$. A principal fácies reservatório identificada nestas seções está localizada próxima ao contato com a Formação Outeiro, apresentando como características marcantes valores de raios gama e densidade ligeiramente inferiores à média da unidade em cada poço, o que indica baixo teor de pelitos e significativa porosidade. Seis dos dezesseis poços das seções exibem resistividade superior a 20 ohm.m, constituindo potenciais reservatórios de hidrocarbonetos

Sobrepostos à Formação Quissamã, os calcilutitos e margas da Formação Outeiro têm sua distribuição fortemente controlada pelo arcabouço estrutural: áreas elevadas em função de falhamentos normais exibem as menores espessuras dessa unidade (ausente nos poços 3BD_0013 e 1RJS_0181A), enquanto regiões abatidas, na porção nordeste de Linguado e centro-oeste de Pampo, chegam a superar os $100 \mathrm{~m}$. Os pelitos da Formação Ubatuba, com índices de raio gama superiores a $70{ }^{\circ} \mathrm{API}$, recobrem a Formação Outeiro, intercalando-se a depósitos arenosos de espessura entre 20 e 60 $\mathrm{m}$ pertencentes à Formação Carapebus, de idade cenomaniana.

A presença de falhas na área limítrofe entre os campos de Linguado e Pampo é expressiva na seção Badejo - Linguado - Pampo, delimitando 


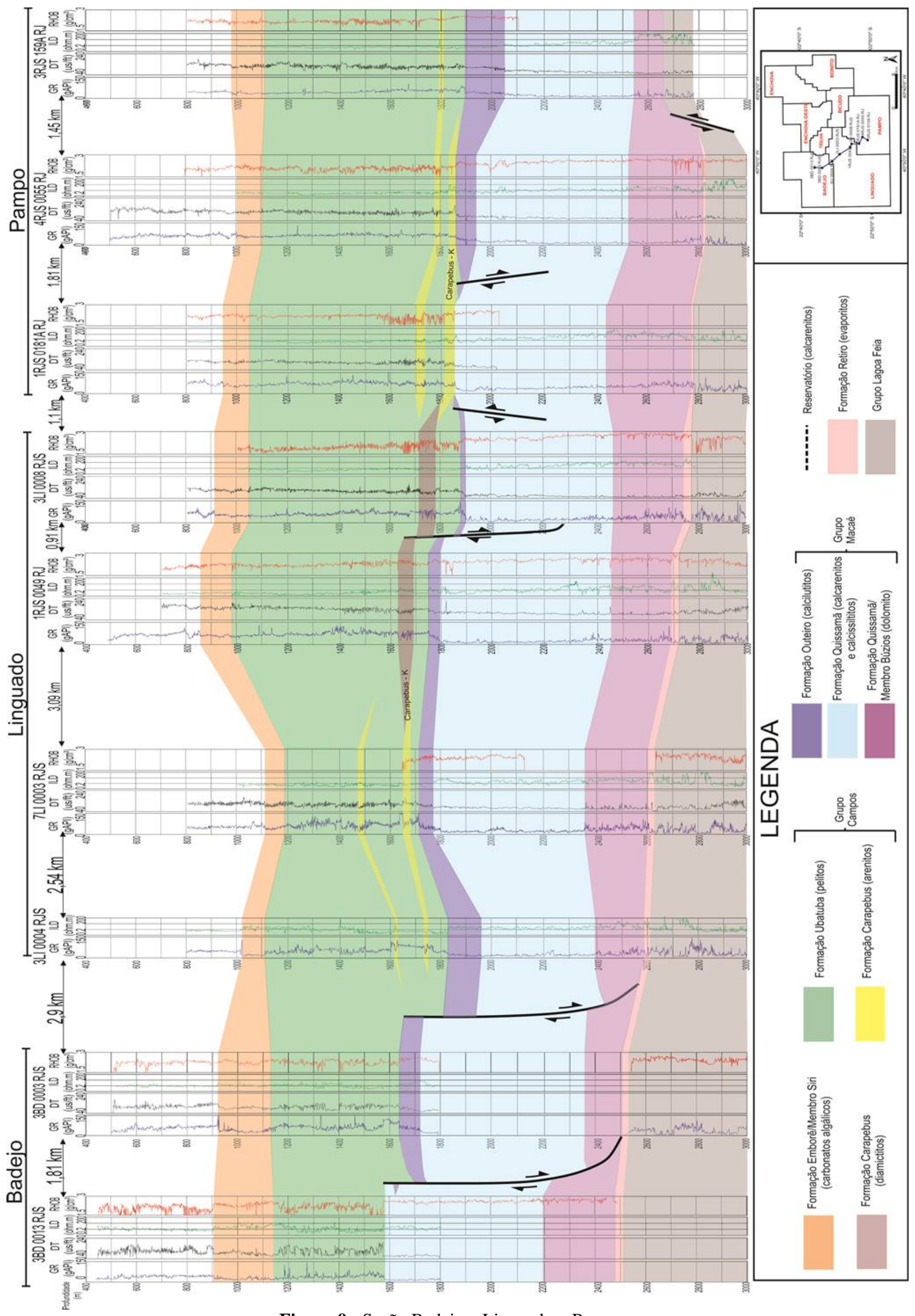

Figura 9 - Seção Badejo - Linguado - Pampo. 


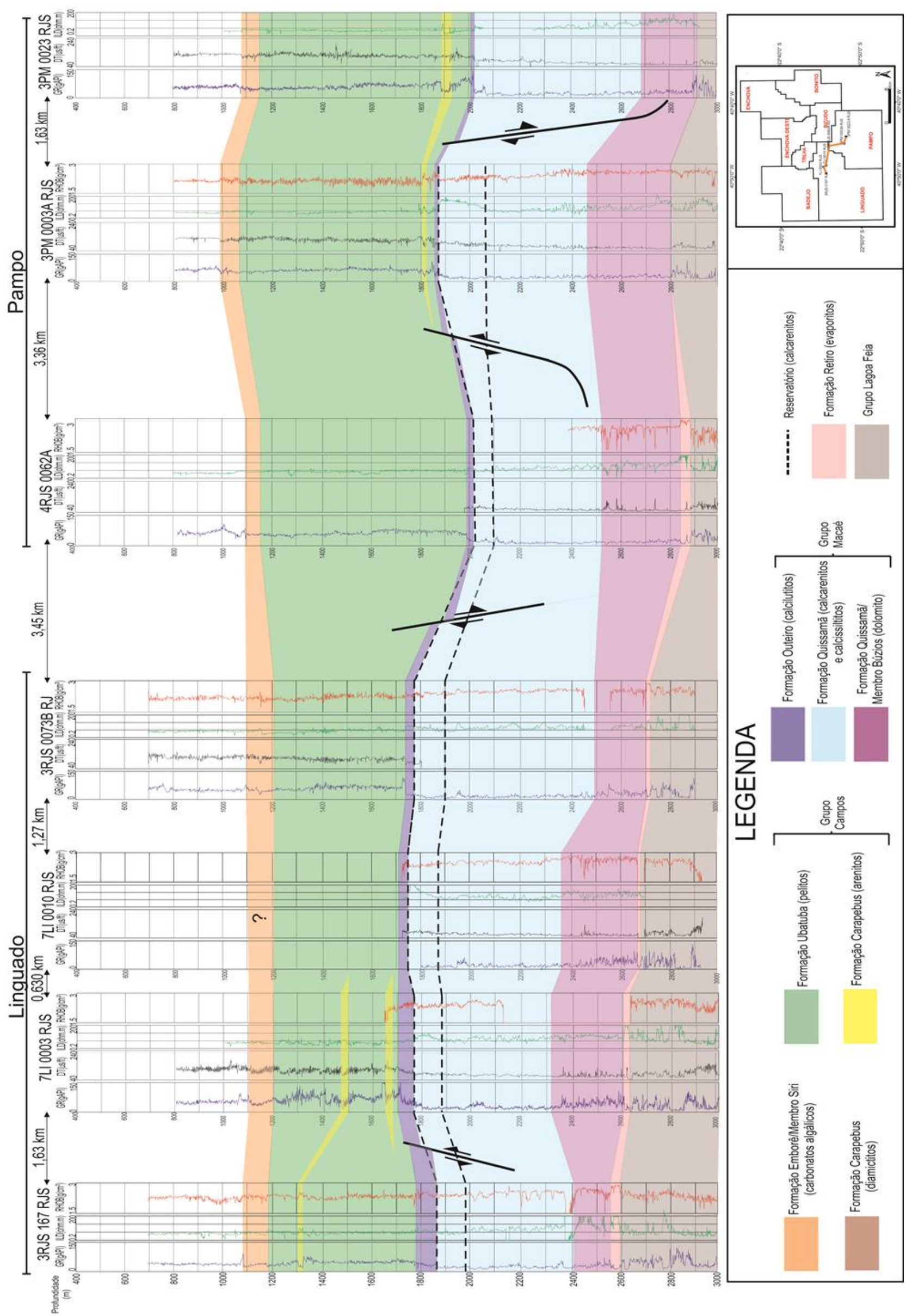

Figura 10 - Seção Linguado - Pampo. 
um sistema graben-horst-graben local, com o bloco soerguido localizando-se na região dos poços 1RJS_0181A e 3PM_0003A. O mesmo padrão estrutural pode ser observado na seção Linguado - Pampo, com presença de um horst na porção nordeste do campo de Linguado (poços 7LI_0003, 7LI_0010, 3RJS_0073B), adjacente a um graben na posição do poço 4RJS_0062A.

Constatou-se, por meio da análise dos perfis de radioatividade, que os poços considerados nos campos de Enchova Oeste, Badejo e Trilha não possuem acumulações relevantes de hidrocarbonetos em meio à porção superior da
Formação Quissamã, uma vez que os valores de ILD nestas áreas não ultrapassam (10 ohm.m), considerando-se o intervalo albiano.

O contexto geológico da região estudada foi detalhado por meio de seções sísmicas $2 \mathrm{D}$ e $3 \mathrm{D}$, conforme exemplificado na figura 11 , onde é possível discernir dois padrões estruturais principais. O primeiro, dominante nos estratos sotopostos à camada evaporítica (pré-sal), caracteriza-se por falhas normais planares, de mergulho elevado. Já nos litotipos do pós-sal, são comuns falhamentos lístricos de grande extensão, gerando abatimento e soerguimento de blocos, além de feições do tipo rollover.

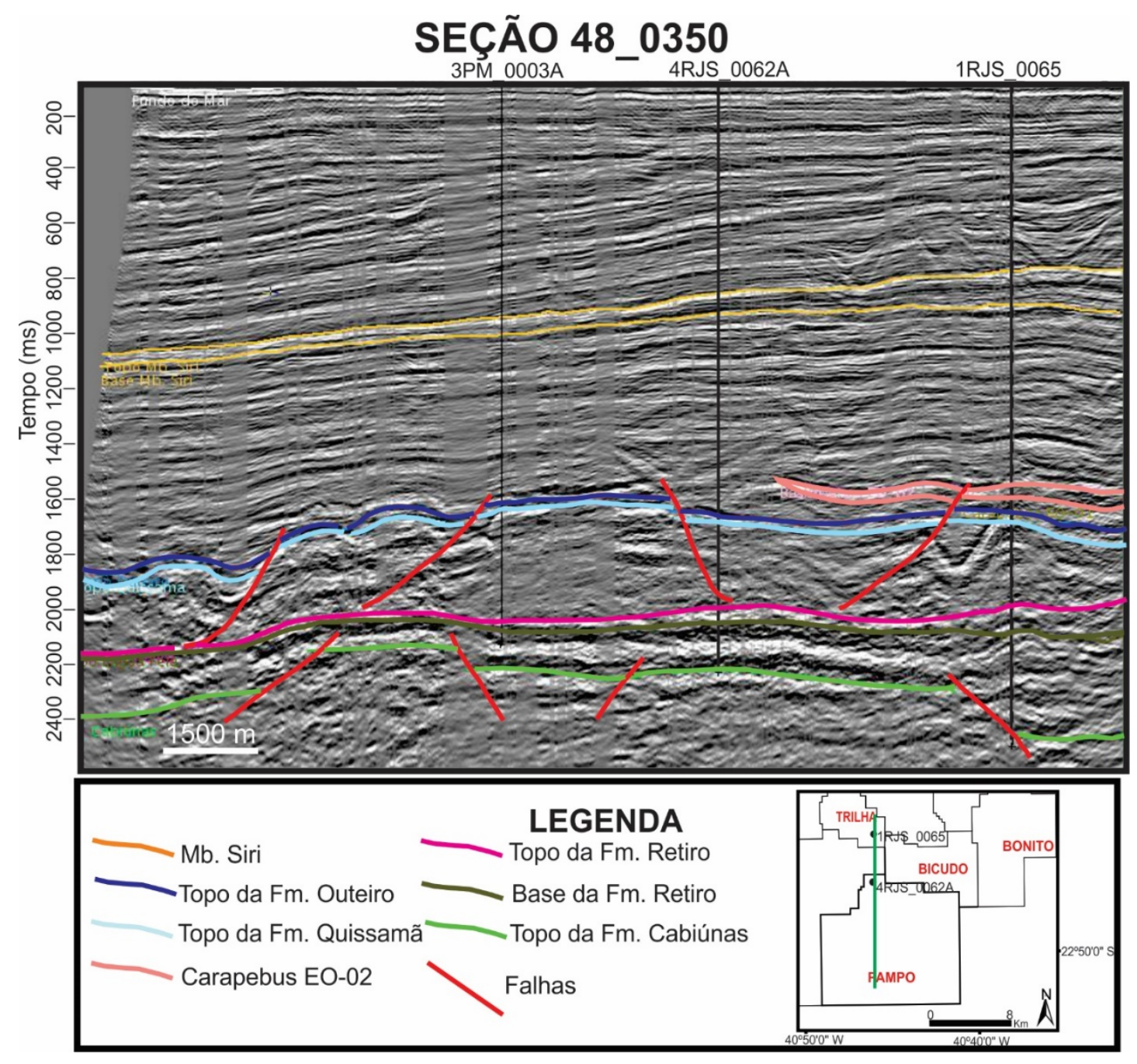

Figura 11 - Seção 48_0350.

A seção apresentada (48_0350), de orientação N-S, compreende a porção leste dos campos de Trilha e Linguado, além da região centro-norte de Pampo. O alto estrutural que inclui o poço 3PM_0003A, descrito na correlação estratigráfica, está claramente representado nesta linha sísmica, bem como o graben à altura do poço 4RJS_0062A, próximo ao limite Pampo - Linguado.

Para compreender melhor a configuração desta feição, uma seção perpendicular à 48_0350, orientada a E-W e abrangendo a porção leste de Linguado e centro - norte de Pampo, foi interpretada e segue expressa na figura 12 (Seção 48_0358).

Nesta linha, pode-se observar que o alto 
considerado é limitado por dois falhamentos principais, associados a uma falha que soergue os estratos do pós-sal em direção ao centro do campo de Linguado, e outra que promove significativo abatimento de toda a seção em direção ao extremo leste de Pampo.

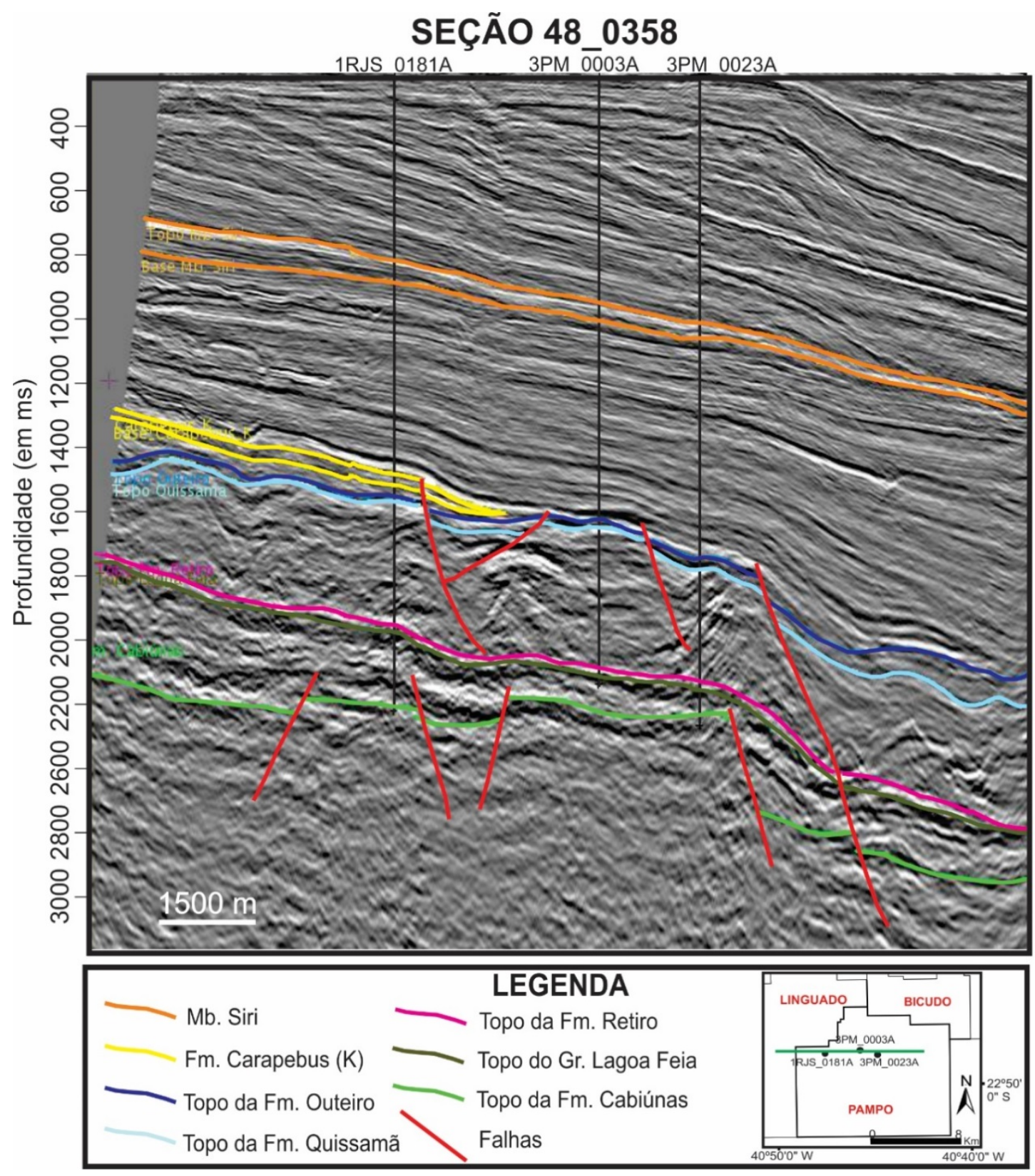

Figura 12 - Seção sísmica 48_0358.

Um mapa de contorno estrutural para o nível reservatório considerado (topo da Formação Quissamã) foi confeccionado, conforme expresso na Figura 13. O mesmo padrão de falhamentos NE-SW foi constatado nos estratos albianos, bem como o mergulho geral de rumo sudeste. Destaca-se neste mapa a presença de uma feição elevada na região sudoeste da área de estudos (campo de Pampo), onde está incluso o poço 3PM_0003A. Esta estrutura, que aparece delimitada por quatro falhamentos normais, corresponde ao Domo de Pampo, descrito por Baumgarten \& Scuta (1989) e
Guardado et al. (1989). Sua origem estaria relacionada ao início da tectônica halocinética, durante o Albiano Inferior.

$\mathrm{Na}$ porção leste da região abordada, os campos de Enchova e Bonito apresentam um mesmo padrão estrutural para a Formação Quissamã, no qual predomina uma sucessão de falhamentos NE-SW, algumas vezes delimitados por falhas NW-SE. Este sistema cria estruturas dômicas com alongamento paralelo às falhas, onde se situam os poços 1RJS_0022(Enchova), 3BO_0003 e 1RJS_0029 (Bonito), todos produtores no intervalo albiano. 


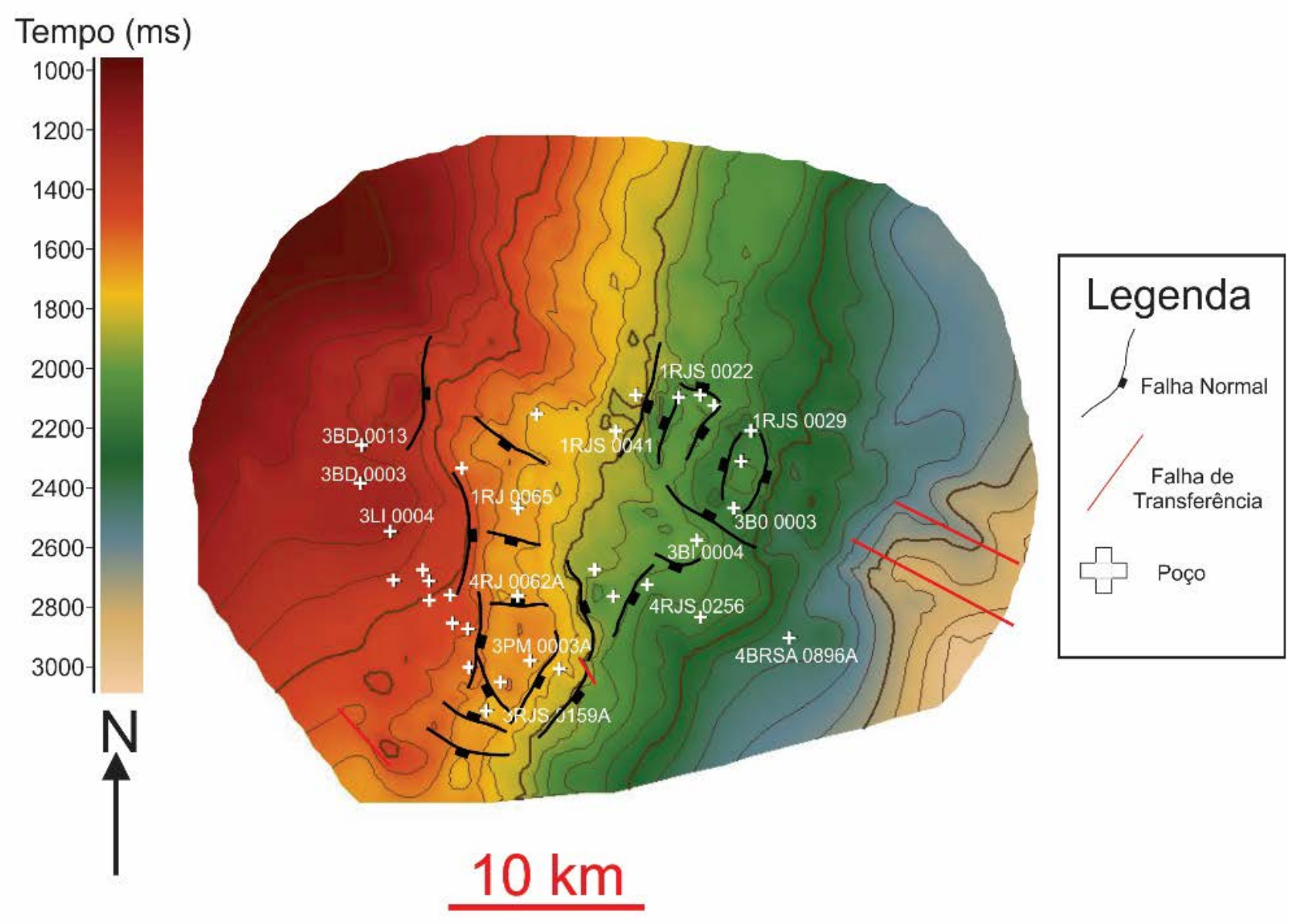

Figura 13 - Mapa de contorno estrutural da Formação Quissamã.

\section{ANÁLISE ESTRUTURAL - ESTRATIGRÁFICA}

As acumulações petrolíferas identificadas no topo da Formação Quissamã podem ser agrupadas em três regiões, de acordo com o contexto geológico local: Domo de Pampo, campos de Enchova - Bonito e campo de Bicudo. A principal característica comum destas ocorrências é a rocha selante que capeia os níveis reservatório, correspondente aos calcilutitos e margas da Formação Outeiro.

Os valores de resistividade e dados de perfis compostos indicam três poços produtores no intervalo albiano na área do Domo de Pampo (1RJS_0181A, 3PM_0003A, 3PM_0023). As seções sísmicas e correlações estratigráficas locais (Figuras 9, 10,11 e 12) evidenciam que o poço 3PM_0003A situa-se na porção central do domo, enquanto o poço 1RJS_0181A está localizado num alto a oeste deste. Uma proeminente falha separa ambas as feições, abatendo a região do domo em relação ao campo de Linguado.
O terceiro poço (3PM_0023) foi perfurado a leste do Domo de Pampo, sendo classificado como "extensão - produtor de óleo", segundo dados oficiais da ANP (2016). Esta área está situada entre duas falhas, conforme exposto na Figura 12: a primeira, a oeste do poço 3PM_0023, promove o abatimento deste em relação ao domo, enquanto a segunda, a leste do poço, separa os campos de Pampo (bloco alto) e Bicudo (bloco baixo).

Portanto, pode-se atribuir caráter estrutural às trapas em meio à região do Domo de Pampo: os três poços analisados estão em posições de alto estrutural relativo a áreas adjacentes, cujas falhas impedem a migração lateral do óleo em função da justaposição de camadas pouco permeáveis (Formação Outeiro ou Formação Ubatuba) às rochas calcareníticas da Formação Quissamã. Este contexto pode ser observado na Figura 14, na qual aparecem também dois poços não produtores (4RJS_00062A e 3RJS_0159A), situados em baixos locais a norte e a sul do Domo de Pampo. 


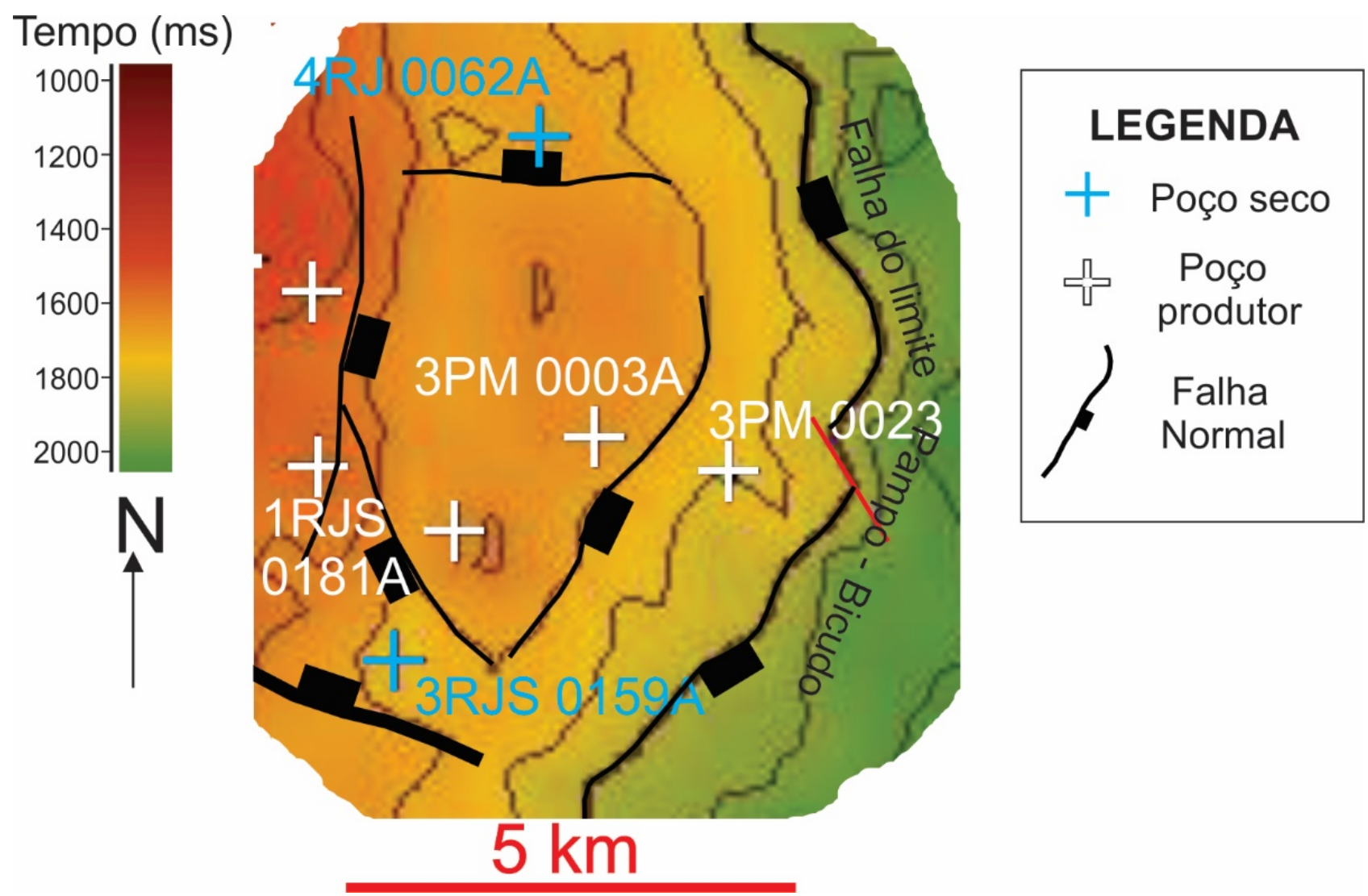

Figura 14 - Detalhe do Domo de Pampo, representando os poços produtores (em altos estruturais locais) e secos (baixos locais).

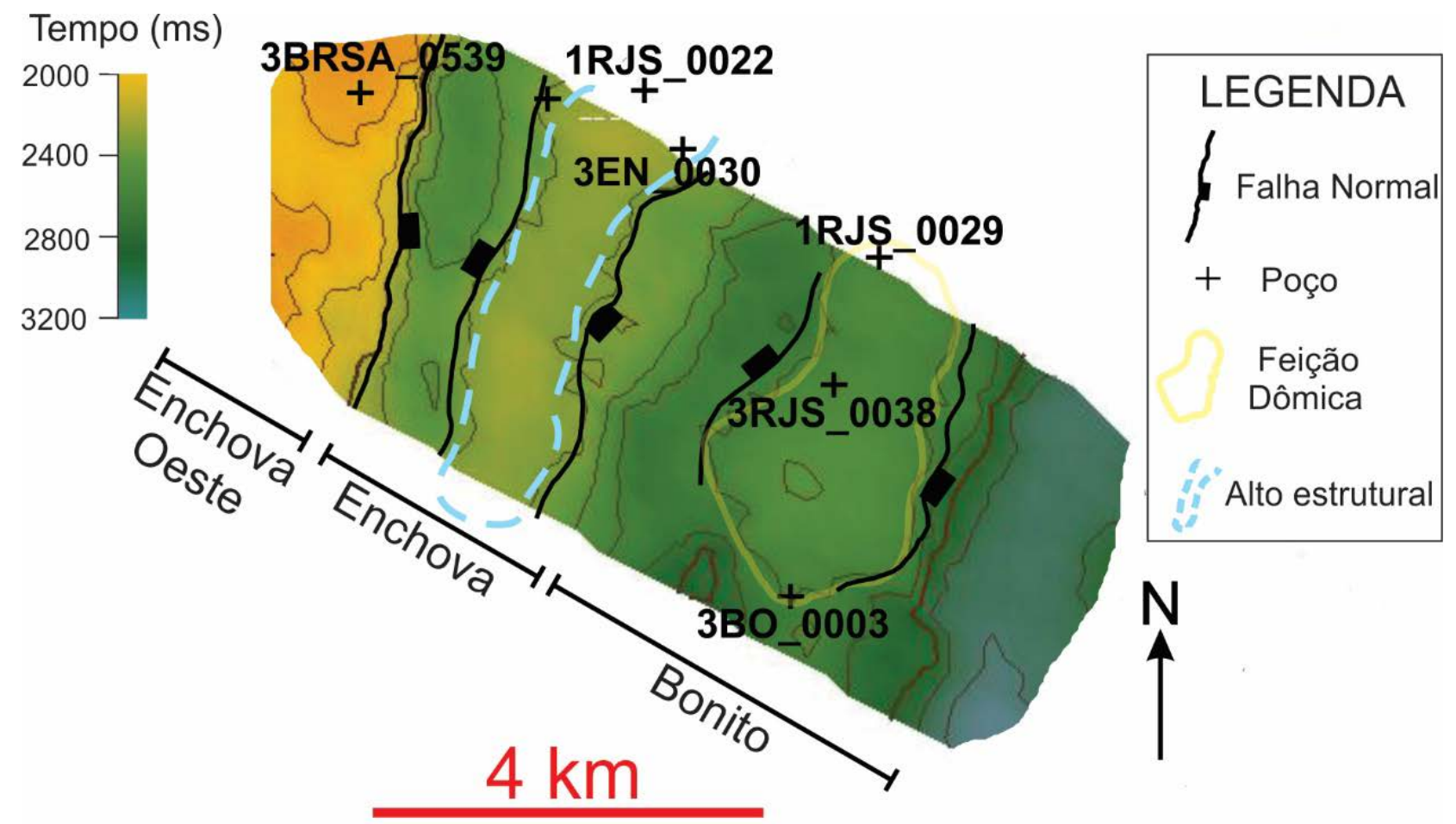

Figura 15 - Contorno estrutural do Topo da Formação Quissamã na região dos campos de Enchova - Bonito, com destaque à estrutura dômica no campo de Bonito (amarelo) e o alto estrutural local em Enchova (azul). 
Outra área que abriga reservas petrolíferas em meio à Formação Quissamã consiste na porção limítrofe entre os campos de Enchova e Bonito, onde os poços 1RJS_0022, 3EN_0030 (Enchova), 3RJS_0038, 1RJS_0029 e 3BO_0003 (Bonito) são produtores de óleo e/ou gás no intervalo albiano. O mapa de contorno estrutural dos calcarenitos albianos para a região, em detalhe, (Figura 15) revela a presença de sucessivos falhamentos sintéticos e antitéticos, com orientação NE-SW.

Como se pode observar, este sistema de falhas compartimenta o arcabouço geológico local, criando, em Enchova, um alto estrutural alongado no sentido NE-SW, paralelo aos falhamentos presentes. No campo de Bonito, este padrão cria uma estrutura dômica, com eixo maior de direção NE-SW, limitada a sudeste e noroeste por falhas normais, com mergulho baixo de rumo SW em sua borda sudeste, representando um abatimento da Formação Quissamã nessa direção.

Todas as ocorrências de hidrocarbonetos constatadas na região estão relacionadas às estruturas descritas. Em Enchova, os poços 1RJS_0022 e EN_0030 estão situados na porção central do alto descrito, propiciando a acumulação de hidrocarbonetos no topo da Formação Quissamã. Situação similar ocorre no domo existente na porção sul de Bonito, onde estão situados os três poços produtores do campo. No entanto, os limites sudoeste e nordeste da estrutura não são marcados por descontinuidades estruturais, mas pelo adelgaçamento da Formação Quissamã e consequente espessamento das margas e calcilutitos da Formação Outeiro. Dessa maneira, ocorre uma variação lateral de fácies calcareníticas para fácies de menor energia (calcissiltitos e calcilutitos) na direção NESW, caracterizando trapas de natureza estratigráfica nesse sentido.

Assim, as acumulações petrolíferas na região de Enchova e Bonito são controladas por trapas mistas, estratigráficas e/ou estruturais, relacionadas aos falhamentos de direção NE-SW e à variação lateral de fácies no sentido NE-SW. O padrão estrutural descrito para a região corrobora o trabalho de Baumgarten (1986), que descreve duas estruturas dômicas principais na porção meridional dos campos de Enchova e Bonito. O mesmo autor enfatiza que a variação lateral e vertical das fácies de alta energia para aquelas de baixa energia ocorre como resposta à halocinese albiana, que gera baixos deposicionais propícios à deposição de litotipos pelíticos.

A terceira região que concentra acumulações petrolíferas em meio à Formação Quissamã consiste no campo de Bicudo, onde os poços 4RJS_0039A, 4RJS_0161 e 3BI_0004 são produtores comerciais ou subcomerciais de óleo e/ou gás.

Considerando-se as seções Enchova Oeste - Trilha - Bicudo (Figura 7) e Enchova Bicudo - Bonito (Figura 8), bem como o mapa de contorno estrutural da Formação Quissamã (Figura 14), percebe-se que o poço 3BI_0004 está situado num alto estrutural ao nível do Grupo Macaé: uma falha o separa do poço 4RJS_0134 a sudoeste, enquanto outro falhamento, que limita os campos de Bicudo e Bonito, abate a região do poço 3BO_0003. A Figura 16 consiste numa seção esquemática que ilustra o contexto geológico local, evidenciando o caráter estrutural do trapeamento de hidrocarbonetos no poço 3BI_0004.

Situados no extremo oeste de Bicudo, os poços 4RJS_0039A e 4RJS_0161 foram perfurados próximos à falha que separa este campo de Pampo, promovendo um desnível de 200 m no topo da Formação Quissamã em relação ao poço 3PM_0023.

Inicialmente, o contexto estrutural local parece desfavorável à presença de acumulações petrolíferas nestes poços. No entanto, a análise sísmica regional permitiu a identificação de estruturas do tipo rollover próximas ao plano da Falha Pampo - Bicudo.

Como se pode perceber na Figura 17 (seção sísmica), o poço 4RJS_0039 intercepta a crista da anticlinal de rollover, onde estaria presente a maior espessura da coluna de hidrocarbonetos. A proximidade espacial entre os poços 4RJS_0039 e 4RJS_0161, bem como a posição estrutural constante do topo da Formação Quissamã em ambos (aproximadamente a $2050 \mathrm{~m}$ ) sugere o mesmo contexto para as acumulações petrolíferas em cada um deles. Dessa maneira, atesta-se o caráter estrutural das trapas nessa região. 


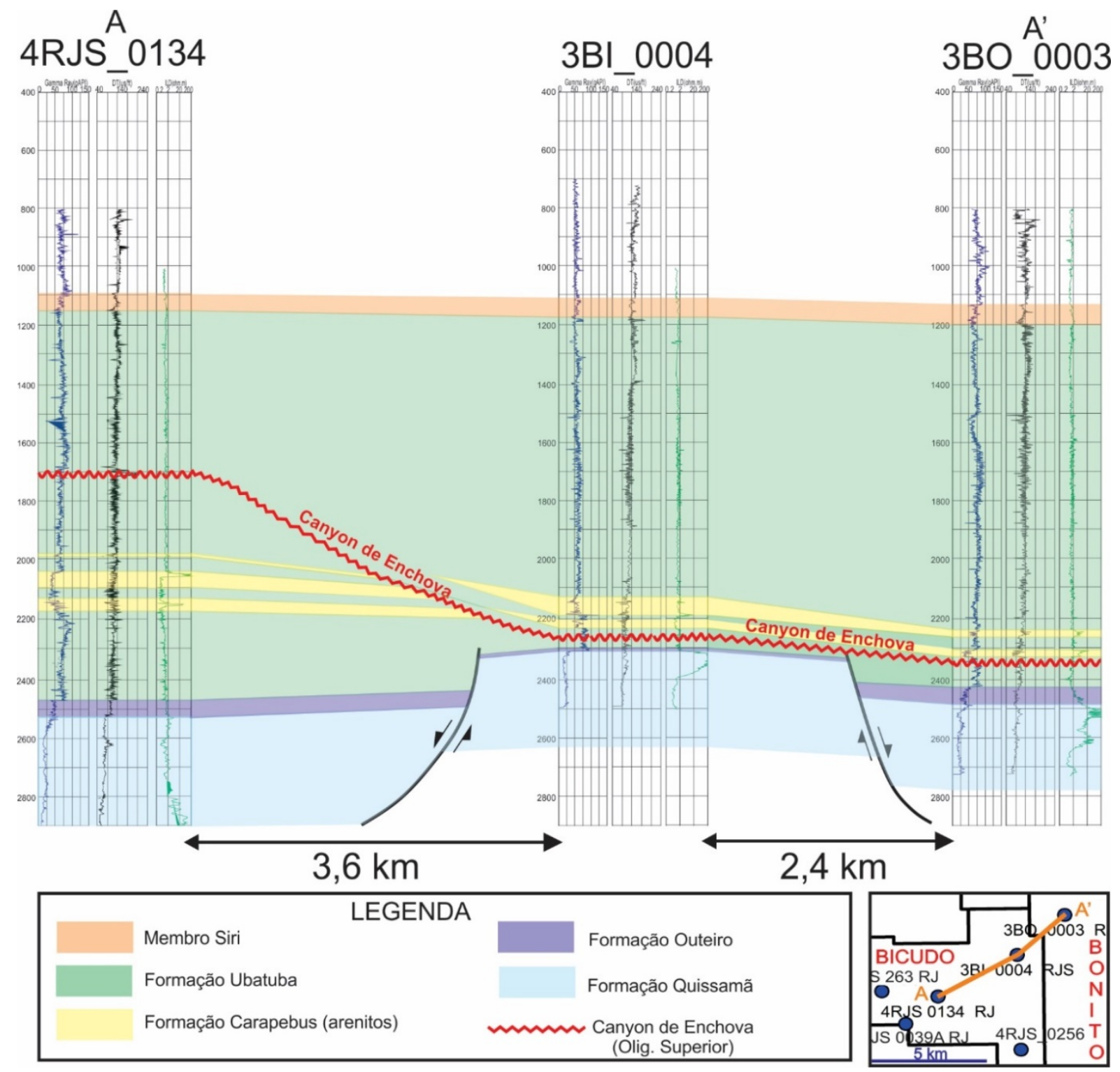

Figura 16 - Seção esquemática entre os campos de Bicudo e Bonito, representando o alto estrutural local, ao nível do Grupo Macaé, em que está inserido o poço 3BI_0004.

\section{CONCLUSÕES}

A partir da confecção de quatro seções estratigráficas, compostas por 33 poços, em conjunto à análise de 60 linhas sísmicas 2D e um volume sísmico 3D de aproximadamente 90 $\mathrm{km}^{2}$, foi possível caracterizar os mecanismos principais que controlaram as acumulações de hidrocarbonetos em meio à porção superior dos calcarenitos da Formação Quissamã, em oito campos petrolíferos situados na porção sudoeste da Bacia de Campos.

A interpretação dos dados sísmicos e mapas elaborados possibilitou a determinação do padrão estrutural regional, com falhamentos normais de direção NE-SW dominantes e zonas de transferência subordinadas, orientadas a NW-SE. Na porção sudoeste da área estudada, importante feição dômica foi caracterizada ao nível da Formação Quissamã, correspondente ao Domo de Pampo. Estrutura de natureza semelhante, em menor escala, foi também identificada na porção sul do campo de Bonito, associada a um sistema de falhamentos sintéticos e antitéticos que condicionam a produção de hidrocarbonetos localmente. Integrando-se os resultados obtidos, foram caracterizadas as condições que possibilitaram a existência das principais acumulações petrolíferas identificadas. A Formação Quissamã tem seus reservatórios descritos nos campos de Pampo e Linguado condicionados por trapas estruturais, relacionadas a falhamentos que soerguem os blocos na porção oeste do primeiro (região do Domo de Pampo) e rumo ao centro do segundo campo. 

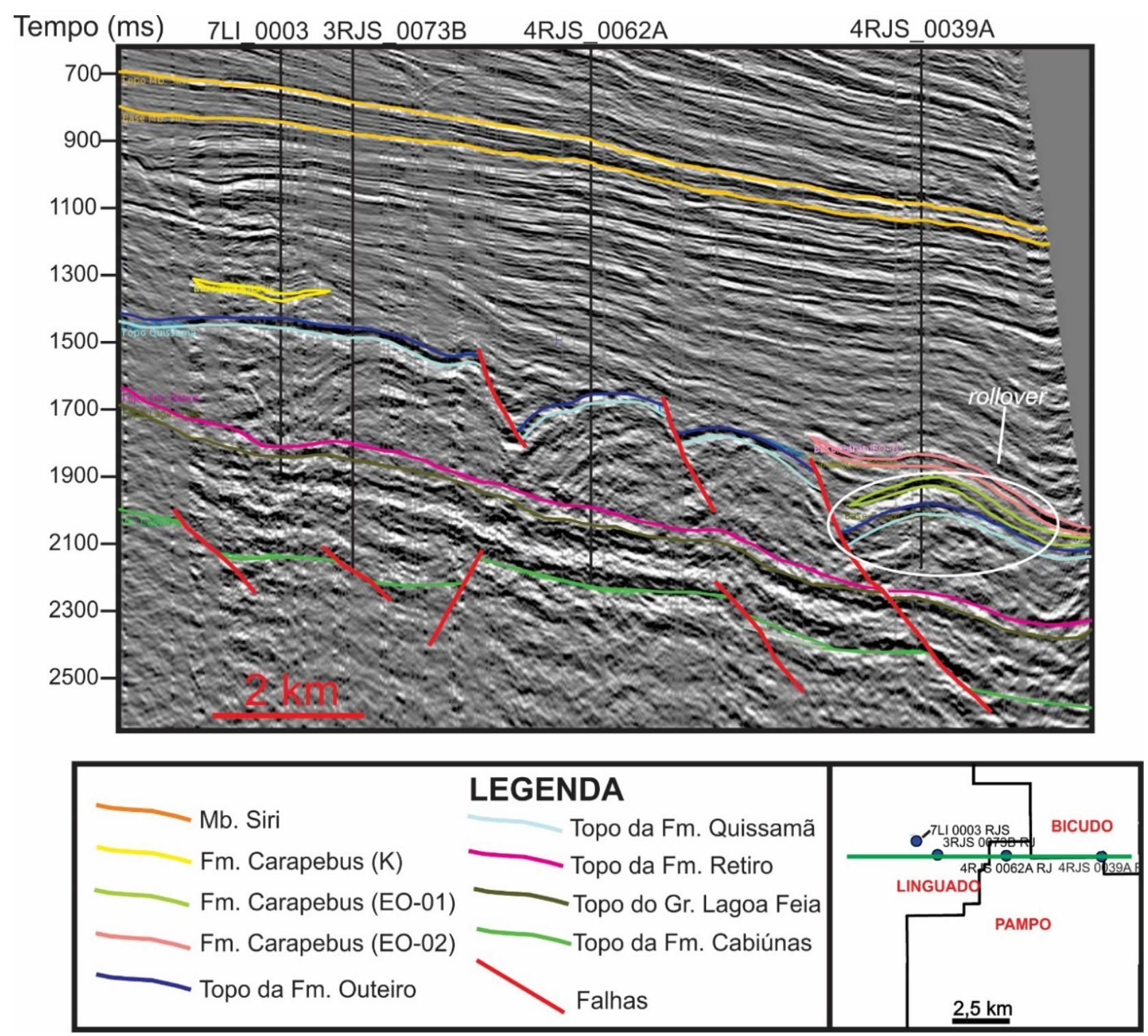

Figura 17 - Seção sísmica 48_0356 interpretada. Em destaque (branco), está expressa a feição de rollover no poço 1RJS_0039A.

As armadilhas presentes nos campos de Bonito e Enchova foram classificadas como mistas, relacionadas tanto a altos estruturais e domos locais, quanto à variação lateral de fácies em baixos deposicionais.

Em Bicudo, as trapas descritas mostram caráter estrutural, apresentando-se como feições de rollover nos poços 1RJS_0039A e 4RJS_0161. Na porção nordeste, uma falha de grande extensão e rejeito separa as áreas de Bicudo e Bonito, abatendo o bloco neste último campo. Esta feição ocorre associada a outro falhamento, a sudoeste do poço 3BI_0004, promovendo o soerguimento da Formação Quissamã na região deste poço.

Embora o Canyon de Enchova tenha sido descrito ao longo de todos estes campos, sua superfície erosiva não atinge, nesta área, a Formação Quissamã, restringindo-se a um fator condicionante de acumulações petrolíferas apenas nos estratos turbidíticos da Formação Carapebus.

\section{AGRADECIMENTOS}

Os autores estendem seus agradecimentos ao LISG (Laboratório de Interpretação Sísmica e Geológica), pela infraestrutura fornecida, à ANP, pela concessão dos dados utilizados, e à Landmark, pela disponibilização do software utilizado na interpretação dos dados sísmicos. 


\section{REFERÊNCIAS}

AGÊNCIA NACIONAL DO PETRÓLEO - ANP - Boletim da Produção de Petróleo e Gás Natural- Agosto de 2016. Site: www.anp.gov.br. Acessado em 15/08/2016.

AGÊNCIA NACIONAL DO PETRÓLEO - ANP. Sumário Executivo do Campo de Trilha - Mar. de 2016. Site: www.anp.gov.br. Acesso em 09/07/2016.

AGÊNCIA NACIONAL DO PETRÓLEO - ANP. Sumário Executivo do Campo de Linguado - Mar. de 2016. Site: www.anp.gov.br. Acesso em 10/07/2016.

AGÊNCIA NACIONAL DO PETRÓLEO - ANP. Sumário Executivo do Campo de Pampo - Fev. de 2016. Site: www.anp.gov.br. Acesso em 09/07/2016.

ANTUNES, R.L.; SONOKI, N.T.; CARMINATTI, M. The Enchova Paleocanyon (Campos Basin-Brazil): Its OligoceneMiocene History Based on Calcareous Nannoplankton Stratigraphy and Seismostratigraphy. Revista Brasileira de Geociências, v. 18, n. 3, p. 283-290, 1988.

ASMUS, H.E. \& PORTO, R. Diferenças nos estágios iniciais da evolução da margem continental brasileira: possíveis causas e implicações. In: CONGRESSO BRASILEIRO DE GEOLOGIA, 31, Camboriú, 1980. Anais... Camboriú: SBG. 1980, v. 1, p. 225-239.

BANCO DE DADOS DE EXPLORAÇÃO E PRODUÇÃO BDEP - Produção de petróleo e gás natural por campo 2016. Disp. em: <http://www.bdep.gov.br>. Acesso em: 20/07/2016.

BAUMGARTEN C.S. \& SCUTA M.S. Geometria dos corpos carbonáticos do reservatório Macaé (Metade Superior), Campo de Pampo. Boletim de Geociências da Petrobras, v. 3 n. 1/2, p. 49-57. 1988.

BAUMGARTEN, C.S. Campo de Bonito: Relacionamento Tectônica Sedimentação do Albiano ao Eoceno. Boletim Técnico Petrobrás, Rio de Janeiro, v 29, n. 2, p. 261-269, 1986.

BRUHN, C.H.L.; GOMES, J.A.T; DEL LUCCHESE, C.; JOHANN, P.R.S. Campos Basin: reservoir characterization and management-Historical overview and future challenges. OTC Proceedings Contribution, n. 15220, 12p. 2003.

CAINELLI, C. \& MOHRIAK, W.U. Geology of atlantic eastern brazilian basins. In: AAPG INTERNATIONAL CONFERENCE \& EXHIBITION, Rio de Janeiro, 1998. Geology part II, Short Course Notes...Rio de Janeiro Brazilian.

CHANG, H.K.; KOWSMANM, R.O.; FIGUEIREDO, A.M.F. "Novos Conceitos sobre o Desenvolvimento das Bacias Marginais do Leste Brasileiro”. In: RAJA GABAGLIA, G.P. \& MILANI, E.J. (Eds.). Origem e Evolução de Bacia Sedimentar. Rio de Janeiro, Petrobras, p. 269-89, 1990.

DEMERCIAN, S.P.; SZATMARI, P.R.; COBBOLD, P.R. Style and pattern of salt diapirs due to thin-skinned gravitational gliding, Campos and Santos basins, offshore Brazil. Tectonophysics, v. 228, p. 393-433, 1993.
DIAS, J.L.; SCARTON, J.C.; ESTEVES, F.R.; CARMINATTI, M.; GUARDADO, L.R. Aspectos da evolução tectonosedimentar e a ocorrência de hidrocarbonetos na Bacia de Campos. IN: RAJA GABAGLIA, G.P.; MILANI, E.J. (Coords.) Origem e evolução de Bacias Sedimentares. Petrobrás, p. 333-360, 1990.

DIAS-BRITO, D. Evolução paleoecológica da Bacia de Campos durante a deposição dos calcilutitos, margas e folhelhos da Formação Macaé (Albiano e Cenomaniano). Boletim Técnico da Petrobras, v. 25, n. 2, p. 84-97, 1982.

FIGUEIREDO, A.M.F. \& MOHRIAK, W.U. A Tectônica Salífera e as Acumulações de Petróleo da Bacia de Campos. In: CONGRESSO BRASILEIRO DE GEOLOGIA, 33. 1984. Rio de Janeiro. Anais... Rio de Janeiro: SBG, p. 1380-1394.

GUARDADO, L.R. \& ARSO, L.R. Cendrio regional e expressões sísmicas dos turbiditos da Bacia de Campos. Petrobras/Depex. Relatório Interno, 1984.

GUARDADO, L.R.; GAMBOA, L.A.P. \& LUCCHESI, C.T. Petroleum Geology of the Campos Basin, Brazil, a Model for a Producing Atlantic Type Basin. AAPG Memoir 48. Tulsa, American Association of Petroleum Geologists, n. 48, p. 379, 1989.

LOPES, M.F.B.V. Caracterização Geológica da Província Petrolífera de Campos. Rio de Janeiro, 2004. 196p. Dissertação (Mestrado), Universidade Federal do Rio de Janeiro.

MILANI, E.J. \& ARAUJO, L.M. Recursos Minerais Energéticos: Petróleo. In: BIZZI, L.A; SCHOBBENHAUS, C.; VIDOTTI, R.M.; GONÇALVES, J.H. (Eds). Geologia, tectônica e recursos minerais do Brasil. Brasília: CPRM, 2003. Capítulo X, parte IV.

RANGEL, H.D; MARTINS, F.A.L.; ESTEVES, F.R., FEIJÓ, F.J. Bacia de Campos. Boletim de Geociências da Petrobrás, v. 8, p. 203-218, 1994.

SPADINI, A.R., ESTEVES, F.R., DIAS-BRITO, D., AZEVEDO, R.L.M., RODRIGUES, R. The Macaé Formation, Campos basin, Brazil: Its evolution in the context of the initial history of the South Atlantic. Revista Brasileira de Geociências, v. 18, n. 3, p. 261-272, 1988

WINTER, R.W.; JAHNERT, R.J.; FRANÇA, A.B. Bacia de Campos. Boletim de Geociências da Petrobrás, v. 15, n. 2. Rio de Janeiro, p. 511-529, 2007. 